\title{
Epidemiological, clinical and progressive spectrum of measles cases admitted to „Dr. Victor Babes“ Clinical Hospital for Infectious and Tropical Diseases, Bucharest during the actual outbreak
}

\author{
Geta Vancea ${ }^{1,2}$, Andreea Stoenescu ${ }^{1}$, Irina lanache ${ }^{1}$, Cristina Iordache ${ }^{1}$, \\ Eugenia Ungureanu', Carmen Apostol', Gh. Enache', Dana Ispas', Nicoleta Voicu-Parvu', \\ D. Serban ${ }^{1,2}$, Roxana Cebuc ${ }^{1}$, Alexandra Malciolu-Nica', Ana-Maria Dascalu ${ }^{1,2}$, \\ Emanoil Ceausu ${ }^{1,2}$, Petre Calistru ${ }^{1,2}$ \\ 1"Dr. Victor Babes" Clinical Hospital for Infectious and Tropical Diseases, Bucharest, Romania \\ 2"Carol Davilla" University of Medicine and Pharmacy, Bucharest, Romania
}

\begin{abstract}
Introduction. Starting with 2016 Romania had to face an alarming measles outbreak due to the continuous poor vaccination coverage. The outbreak associated an increased number of complications and deaths. Materials and methods. We performed a retrospective study, on a group of patients with measles, admitted to "Dr. Victor Babes“ Hospital. Epidemiological data, clinical characteristics and the results of the biological samples were obtained from the patient's medical records between January 2016 and December 2017.

Results. Out of the 632 patients, 341 (53.9\%) were males. Most of them (39.2\%) were children, between 1 and 4 year-old, while $19.6 \%$ were infants.

A quarter of the patients $(31.3 \%)$ had familial contact with a measles case. The vaccination history was unknown in $44.3 \%$ cases; almost half of the patients $(47.1 \%)$ were unvaccinated.

Almost all of them developed viral complications, $84.1 \%$ being diagnosed with interstitial pneumonia. Bacterial pneumonia was diagnosed in $15.0 \%$ cases, out of which $45.2 \%$ were also associated with respiratory failure. Six patients required transfer to the pediatric intensive care unit for respiratory support and 2 died. Other complications were: laryngitis $8.2 \%$, otitis $12.0 \%$ of the cases. Also $61.77 \%$ of the patients were diagnosed with enterocolitis. There was no case complicated with encephalitis. 101 (15.9\%) patients developed liver cytolysis, while dyselectrolytemia was present in $94(14.8 \%)$ cases.

Conclusions. The number of patients diagnosed with measles during the last years registered an alarming increase, especially in children under 4 year old, with a high number of complications. We consider it mandatory to apply the vaccination program to ensure an optimal vaccine coverage, useful both in stopping the current outbreak and in preventing future outbreaks.
\end{abstract}

Keywords: measles, outbreak, complications, death, vaccination

\section{INTRODUCTION}

Measles is an acute and extremely contagious disease (index of contagiousness $>95 \%$ ), determined by the infection with the measles virus (Morbillivirus, Paramyxoviridae family). The transmission is done by way of the air, through respiratory drops, the disease spreading easily from one person to another through sneezing or coughing.
The main symptoms are fever and maculo-papulo-erythematous exanthema, together with coughing, coryza and ocular damage. The first symptoms appear at approximatively 10-11 days after the contact with a sick person and it manifests itself through fever, ocular and respirator catarh and subsequently, after 3-4 days from the appearance of these first symptoms, the maculopapulo-erythema- 
tous characteristic rash with cranio-caudal distribution appears.

The measles virus determines important immunosuppression and measles complications mostly affect children under the age of 5, immunosuppressed people and adults. Complications worth mentioning are: pneumonia, encephalitis, otitis, gastroenterocolitis, laryigotracheo-bronchitis. Subacute sclerosing panencephalitis - is a rare but severe complication that appears at a long time from the acute episode (with an average of 7 years), with progressive degeneration of the central nervous system, being lethal in a percentage of $100 \%$.

During the last three years, Europe and Romania, implicitly, faced a measles epidemic which was on the background of a continuously lower vaccination rate.

In 2016 5,273 measles cases have been reported in 53 European countries. The number of cases was approximately 4 times bigger in the year 2017, when 23,927 people were infected with the measles virus. Over $75 \%$ of the cases were registered in the first half of 2017, mostly in the months of March (2,802 cases), April (2,472 cases) and May (2,244 cases) (1). Romania was the most affected country of the year 2017, with a total of 9,076 reported cases (2). Other countries that have reported and alarming rate of cases were Italy (over 5,000 cases), Greece (967 cases), Germany (929 cases) and France (518 cases). Also, in the year 2017, there were 37 deaths of patients diagnosed with measles, the most being in Romania (26 cases), followed by Italy (4 cases) and Greece ( 2 cases).

The outbreak also continued this year too. Thereby, over 41,000 cases of measles and 37 deaths have been reported in the first half of this year, 43 European countries being affected. France, Georgia, Italy, Russia, Greece, Ukraine and Serbia each faced over 1,000 cases. In Germany 328 cases were reported and in Belgium, Bosnia and Herzegovina there were about approximately 100 cases for each country. The most cases of measles were in Ukraine (over 23,000), while the most deaths were recorded in Serbia (14 cases) $(3,4)$.

According to the last report of the National Institute of Public Health, in Romania during October 2018 , the total number of measles reported cases was 15,395 , of which 59 deaths. The peak of the epidemic was reached in March 2017, when 1,338 cases were reported. Subsequently, there was a decrease in the number of cases registered weekly from 300, during April to June, to 50 in SeptemberOctober (2). Even in this context Romania is still in a full measles epidemic because of poor vaccination coverage.

The objective of the study was to evaluate the incidence of measles in an infectious disease hospital from Bucharest and to identify social-demographic characteristics, epidemiologic characteristics and the clinical evolutions of these patients.

\section{MATERIALS AND METHODS}

We performed a retrospective study on a group of patients with measles, admitted to "Dr. Victor Babes" Infectious and Tropical Diseases Clinical Hospital Bucharest, between January 2016 and December 2017.

Epidemiological data, clinical characteristics and the results of the biological samples were obtained from the patient's medical records and from the hospital's electronic database.

The diagnosis of measles was based on serological tests (IgM measles in plasma) and molecular tests (measles PCR-virus in nasopharyngeal exudate), respectively depending on the epidemiological characteristics (family contact/community, vaccine status).

\section{RESULTS}

The total number of patients diagnosed with measles during the analysed period was 632 , significantly higher in 2017 compared to 2016 (604 vs. 28) (Fig. 1). The total incidence was $1.8 \%$ $(632 / 34,691)$, with numerous variations over the two years of study, from $0.0 \%$ between July and September 2016 and $5.8 \%$ in the same period of 2017 (Table 1).

Out of the 632 patients $341(53.9 \%)$ were male and $330(52.2 \%)$ were from urban environments. The median age at measles diagnosis was 4 years with a minimum of 9 days and a maximum of 49 years. Consequently, most patients were $1-4$ years old (39.2\%), while $124(19.6 \%)$ were infants (Table 2).

In terms of epidemiological characteristics about half of the patients, 317/632 (50.1\%), had no 


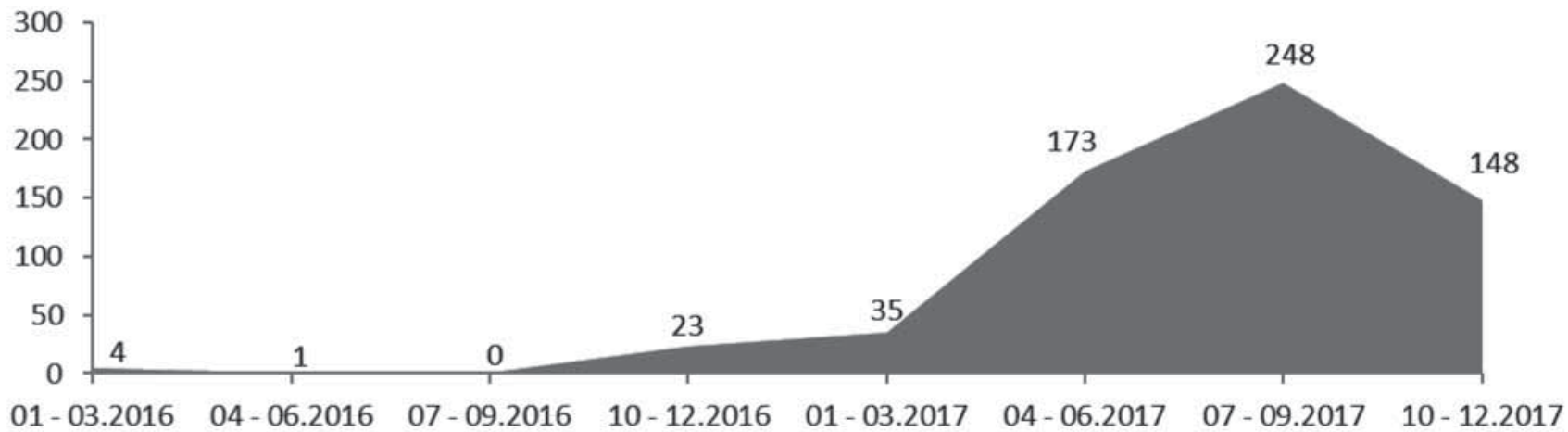

FIGURE 1. Temporal distribution of the number of measles cases

TABLE 1. The temporal distribution of the incidence of measles

\begin{tabular}{|l|c|c|c|c|c|c|c|c|}
\hline & \multicolumn{4}{|c|}{$\mathbf{2 0 1 6}$} & \multicolumn{4}{c|}{$\mathbf{2 0 1 7}$} \\
\hline Month & $\mathbf{0 1 - \mathbf { 0 3 }}$ & $\mathbf{0 4 - \mathbf { 0 6 }}$ & $\mathbf{0 7 - \mathbf { 0 9 }}$ & $\mathbf{1 0 - 1 2}$ & $\mathbf{0 1 - \mathbf { 0 3 }}$ & $\mathbf{0 4 - \mathbf { 0 6 }}$ & $\mathbf{0 7 - \mathbf { 0 9 }}$ & $\mathbf{1 0 - 1 2}$ \\
\hline Total number of sick people $(\mathrm{n})$ & 4,729 & 5,799 & 4,372 & 4,105 & 4,438 & 4,429 & 4,260 & 4,014 \\
\hline Total number of measles cases $(\mathrm{n})$ & 4 & 1 & 0 & 23 & 35 & 173 & 248 & 148 \\
\hline Incidence (\%) & 0.08 & 0.01 & 0.00 & 0.56 & 0.78 & 3.9 & 5.8 & 3.6 \\
\hline
\end{tabular}

TABLE 2. Socio-demographic characteristics of patients diagnosed with measles

\begin{tabular}{|l|l|l|}
\hline Characteristics & & $\begin{array}{l}\text { Total number of measles cases } \\
\mathbf{n}=632\end{array}$ \\
\hline Males & $\mathrm{n}(\%)$ & $341(53.9)$ \\
\hline Urban environments & $\mathrm{n}(\%)$ & $330(52.2)$ \\
\hline Age at diagnosis (years) & The median (interval) & $4(9$ days, 49 years) \\
\hline Distribution on age groups & $\mathrm{n}(\%)$ & \\
$<1$ year & & $124(19.6)$ \\
$1-4$ years & & $248(39.2)$ \\
$5-10$ years & & $113(17.8)$ \\
$11-15$ years & & $60(9.4)$ \\
$16-25$ years & & $35(5.5)$ \\
$25-35$ years & $21(3.3)$ \\
$>35$ years. & $33(5.2)$ \\
\hline
\end{tabular}

known contact with measles, about one third, $197 / 632$ patients $(31.3 \%)$, had family contact and $70(11 \%)$ contacted virus in communities, including the hospital environment, $48 / 632$ (7.5\%).

Concerning the vaccination status, 54/632 (8.5\%) reported incomplete vaccination, 298 patients $(47.1 \%)$ were not vaccinated. 280 patients (44.3\%) did not know the vaccination history (Table 3$)$.

Paraclinical diagnosis was performed by serological tests (IgM measles), which were positive in 422 patients $(66.7 \%)$, while $72(11.3 \%)$ had PCR test from measles-positive nasopharyngeal exudate.

There were 41 patients with comorbidities (cerebral palsy, spastic tetraparesis, epilepsy, cardiac malformations, West syndrome, Down syndrome, chronic interstitial lung disease, heart failure, type
IB glycogenosis, ulcerative colitis). During the disease, several measles associated complications were diagnosed. The vast majority of patients was associated with interstitial pneumonia $(84,1 \%)$.

TABLE 3. Epidemiological data of patients diagnosed with measles

\begin{tabular}{|l|l|l|}
\hline Characteristics & & $\begin{array}{l}\text { Total number of measles cases } \\
\mathbf{n}=632\end{array}$ \\
\hline $\begin{array}{l}\text { Measles contact } \\
\text { Family environment } \\
\text { Hospital environment } \\
\text { Community }\end{array}$ & $\mathrm{n}(\%)$ & $197(31.3)$ \\
Unknown & $\begin{array}{l}78(7.5) \\
70(11.0) \\
317(50.1)\end{array}$ \\
\hline $\begin{array}{l}\text { Vaccination status } \\
\text { ROR* }\end{array}$ & $\mathrm{n}(\%)$ & $54(8.5)$ \\
Incomplete & & $298(47.1)$ \\
vaccination & $280(44.3)$ \\
Not vaccinated & & \\
Unkown & \\
\hline \multicolumn{2}{|l|}{ *ROR = rubella, mumps, measles vaccine } \\
\hline
\end{tabular}


Bacterial overgrowth was diagnosed as a bacterial pneumonia in 95 (15\%) patients, and 43/95 (45.2\%) associated with respiratory failure, most with favourable progression under oxygen therapy, corticotherapy and wide spectrum antibiotics. Six patients required transfer to the paediatric intensive care unit for intubation and mechanical ventilation, 2 of whom had unfavourable evolution and died (Table 4).

Other infectious complications were: bronchiolitis $(13,2 \%)$ laryngitis $(52,8.2 \%)$, otitis $(76$, $12.0 \%)$, while $390(61.7 \%)$ had gastric affection (enterocolitis).

There were no cases of neurological complications in the evaluated patients.

Paraclinical, hepatic cytolysis syndrome was observed in $101(15.9 \%)$ patients. Diselectrolymia, in intrainfectious context, was present in $94(14.8 \%)$ of cases (Table 5).

TABLE 4. Evolution of patients with acute respiratory insufficiency associated with bacterial pneumonia diagnosed in measles

\begin{tabular}{|l|l|l|}
\hline Complications & $\begin{array}{l}\text { Total number of bacterial } \\
\text { pneumonia cases } \\
\text { n=95 }\end{array}$ \\
\hline Respiratory failure & $\mathrm{n}(\%)$ & $43(45.2)$ \\
\hline $\begin{array}{l}\text { Transfer to ATI } \\
\text { unit with IOT and } \\
\text { mechanical ventilation }\end{array}$ & $\mathrm{n}(\%)$ & $6(6.3)$ \\
\hline Death* & & $2(2.1)$ \\
\hline $\begin{array}{l}\text { *In the paediatrically } \\
\text { ATI unit }\end{array}$ & & \\
\hline
\end{tabular}

TABLE 5. Complications associated with measles

\begin{tabular}{|l|l|l|}
\hline Complications & & $\begin{array}{l}\text { Total number of measles cases } \\
\mathbf{n = 6 3 2}\end{array}$ \\
\hline Interstitial pneumonia & $\mathrm{n}(\%)$ & $532(84.1)$ \\
\hline Bacterial pneumonia & $\mathrm{n}(\%)$ & $95(15.0)$ \\
\hline Bronchiolitis & $\mathrm{n}(\%)$ & $13(2.0)$ \\
\hline Laryngitis & $\mathrm{n}(\%)$ & $52(8.2)$ \\
\hline Otitis & $\mathrm{n}(\%)$ & $76(12.0)$ \\
\hline Enterocolitis & $\mathrm{n} \mathrm{( \% )}$ & $390(61.7)$ \\
\hline Liver citolysis & $\mathrm{n} \mathrm{( \% )}$ & $101(15.9)$ \\
\hline Dyselectrolytemia & $\mathrm{n} \mathrm{( \% )}$ & $94(14.8)$ \\
\hline
\end{tabular}

\section{DISCUSSIONS}

The current study was conducted on a significant group of patients diagnosed with measles in an infectious disease hospital in Bucharest, Romania. Starting with 2016 our country has faced a measles epidemic that has extended at an alarming rate because of suboptimal vaccine coverage over the last decade. According to The National Institute of Public Health the number of declared measles cases in Romania has increased, from 2,435 in 2016 to 9,076 in 2017. Similarly, the results of this study, have showed the same ascendant trend, with significant difference between the numbers reported in 2017 (2). The incidence of measles in our hospital's patients has alarmingly increased since the year 2016, reaching a maximum in the period of July-September 2017 and then following a slightly descending trend.

Like the reports of other countries, the incidence of measles has varied according to age groups, measles being mostly diagnosed in children under the age of 10 , the mean of the diagnostic age being 4 years old. The most frequent affected age group was 1-4 years, infants being infected in a lower proportion due to the passive immunity from the mother. According to the reports of the National Institute of Public Health the age group of 1-4 years was the most affected at national level, followed by the age group under 1 year. Therefore, from the beginning of the epidemic, the number of children with ages in this range was significantly bigger compared to other age groups.

In Greece, between May 2017 and March 2018, a total of 2,099 cases of measles were reported. Of these, $69 \%$ were diagnosed in children under the age of 14 years (6). In Italy, in 2017, out of 5,098 patients with measles, $68 \%$ were over 20 years old. Ukraine experienced a major measles epidemic in the first months of this year, $66 \%$ of cases being diagnosed in children and 34\% in adults (12). The United Kingdom recorded 760 cases of measles in the first 7 months of the year 2018 at teenagers and young adults with a probable cause being the lack of vaccination (4).

The measles epidemic has spread in the context of poor immunity against the measles virus. The emergence of this situation was favoured by the ineffective implementation of vaccination programs. A significant percentage of all patients in the study group recognized incomplete or absent vaccination. Approximately one third of our patients had familial contact with the measles virus. According to the World Health Organization, 95\% of eligible people should be vaccinated with 2 doses of antimeasles vaccine to prevent the epidemic $(5,11)$. In 2016 were recorded in Romania $86 \%$ and $76 \%$ in 
the first and second dose vaccination rates respectively (10). The vaccination rates for the two doses varied from one country to other. Thus, Italy reported rates of $87 \%$ and $82 \%$ respectively; France, $90 \%$ and $79 \%$, Greece $97 \%$ and $83 \%$. In the Ukraine, one of the lowest immunization rates in the world was registered in 2016 , with only $4 \%$ of the children vaccinated with the first dose. The situation improved in 2017 , when $93.3 \%$ of children received the first dose of vaccine (9) However, Ukraine was facing at the beginning of 2018 the largest outbreak of measles reported in Europe. Although Portugal recorded vaccination rates of $98 \%$ and $95 \%$ for the 2 doses in 2016, 34 cases of measles were reported between February and May 2017 (8).

The measles virus has respiratory tropism and, in consequence, patients frequently associate complications in the upper respiratory tract but also in the lower respiratory tract, especially pneumonia. Bacterial pneumonia diagnosed in our patients generally had a favourable development, but there were also several complicated cases with respiratory failure. Most of these patients were treated, being previously diagnosed, or in treatment of diverse malformations and diseases: West Syndrome, chronic interstitial lung disease, spastic tetraparesis, epilepsy, ulcerative colitis, cardiac malformations, Down syndrome, flare paraplegia, type IB glycogenosis. 6 patients required transfer to the paediatric intensive care department for respiratory support and IOT with mechanical ventilation. Out of these patients, 2 children associated an unfavourable evolution leading to death.

At national level the number of deaths caused by measles was 13 in 2016, 26 in 2017 and in the present 59 deaths have been reported so far. The biggest number of deaths was reported in Serbia in 2018 (14/778 cases) (13), while Ukraine reported in $2017,7 / 4,782$ deaths (12). In Italy, in the period of 2017-2018, 6/5,255 deaths were declared. Two deaths were reported in France: 1 in the first half of
2017 from the 518 cases reported and the second in February 2018 (7). Between May 2017 and March 2018, from the 2,099 cases reported in Greece, 3 of them finalized with deaths.

There were no cases identified with neurological complications or encephalitis in the analysed group.

Although the measles virus is serologically monotypic, 8 classes (A-H) have been identified in the genetic characterization of wild-type viruses. These, in turn, were divided into 24 genotypes, B, $\mathrm{C}, \mathrm{D}, \mathrm{G}, \mathrm{H}$ classes containing multiple genotypes. No biological differences were found between different genotypes. Also, no association was found between a specific genotype and the severity of the disease and the likelihood of developing subacute sclerosing panencephalitis.

Molecular tests to identify the circulating genotype are not routinely performed in our country. According to literature data, genotype B3 is prevalent in Romania, similar to Italy or Greece, while genotype D8 was identified in France or Italy.

\section{CONCLUSIONS}

The incidence of measles has been alarmingly increasing in recent years in Romania, especially affecting children aged 1 to 4 years. Clinical development may be complicated by bacterial infections requiring management in intensive care units, especially in children with associated comorbidities. In the context of current globalization, with large population movements, it is difficult to achieve the elimination of measles in the absence of a rigorous vaccination program.

The implementation of effective vaccination programs and the adoption of appropriate measures to raise public awareness of the importance of child vaccination and of the risks to which they are exposed by their non-compliance are of the upmost importance in the fight to stop the current outbreak and in preventing future outbreaks.

\section{REFERENCES}

1. European Centre for Disease Prevention and Control. Health topics Measles [internet]. 2017 [cited 2017 Feb. 28]. Available from: http:// ecdc.europa.eu/en/healthtopics/measles/Pages/index.aspx.

2. National Institute of Public Health Romania. Measles situation reports in Romania2018:[Weekly measles reports in Romania p.]. Available

from: http://www.cnscbt.ro/index.php/informari-saptamanale/ rujeola-1/.

3. European Centre for Disease Prevention and Control. Communicable disease threats report: CDTR Stockholm: ECDC; 2018 [updated 2018 Feb. 9].Available from: https://ecdc.europa.eu/en/publications- 
data/communicable-disease-threats-report-4-10-february2018-week-6.

4. European Centre for Disease Prevention and Control. Communicable disease threats report: CDTR Stockholm: ECDC; 2018 [updated 2018 Mar. 9]. Available from: https://ecdc.europa.eu/en/publicationsdata/communicable-disease-threats-report-4-10-march2018-week-10.

5. World Health Organization. WHO/UNICEF estimates of national immunization coverage. Available from: http://apps.who.int/ immunization_monitoring/globalsummary/timeseries/tswucoveragemcr2.html.

6. Hellenic Center for Disease Control and Prevention. Measles surveillance reports [internet]. 2018 [cited 2018 Mar. 9]. Available from: http://www.keelpno.gr/elgr/\%CE\%B1\%CF\% $81 \%$ CF\% $87 \%$ CE\% B9\%CE\%BA\%CE\%B7/measles_highlight2017.aspx.

7. Santé Publique France. Measles outbreak in France. Update of surveillance data as of February 20, 2018. [internet]. 2018 [cited 2018 Mar. 9]. Available from: http://invs.santepubliquefrance.fr/ Dossiersthematiques/Maladies-infectieuses/Maladies-a-preventionvaccinale/Rougeole/Points-d-actualites/Epidemiede-rougeole-enFrance.-Actualisation-des-donnees-de-surveillance-au-20-fevrier-2018.

8. National Health Service \& Directorate General for Health Portugal. Measles outbreak - Update [internet]. 2018 [updated 2018 Mar. 19]. Available from: https://www.dgs.pt/a-direccao-geral-da-saude/ comunicadose-despachos-do-director-geral/surto-de-sarampo-na-regiao-norte6.aspx.
9. World Health Organization. WHO vaccine-preventable diseases: monitoring system. 2017 global summary [internet]. 2018 [cited 2018 Mar. 13]. estimated vaccination coverage and VPD by country ]. Available from: http://apps.who.int/immunization_monitoring/ globalsummary/countries?countrycriteria $\% 5 \mathrm{bcountry} \% 5 \mathrm{~d} \% 5$ $\mathrm{b} \% 5 \mathrm{~d}=\mathrm{SRB}$.

10. World Health Organization. WHO EpiData: monthly reports of measles and rubella surveillance data for the European Region. www.euro.who.int/en/health-topics/diseaseprevention/vaccines-andimmunization/publications/surveillance-and-data/who-epidata.

11. World Health Organization. Seventh meeting of the European Regional Verification Commission for Measles and Rubella Elimination. 2018. www.euro.who.int/en/healthtopics/ communicablediseases/measles-and-rubella/publications/2018/7th-meeting-oftheeuropean-regional-verification-commission-for-measles-and-rubellaelimination-rvc.-report

12. Public Health Centre of the Ministry of Health of Ukraine. The situation with measles stabilizes. A new batch of vaccines is already in the regions. [internet]. 2018 [cited 2018 Mar. 7]. Available from: https://phc.org.ua/news/show/situaciya-iz-zahvoryuvanistyu-na-kirstabilizujetsya-nova-partiya-vakcin-uzhe-v-regionah

13. nstitute of Public Health of Serbia. The current epidemiological situation of measles in the Republic of Serbia [internet]. 2018 [cited 2018 Mar. 13]. Available from: http://www.batut.org.rs/index. php?content=1629. 